\section{Placement of double-lumen tubes with a stylet}

We read with interest the recent report by Lieberman $e t$ al. describing placement of left double-lumen tubes (DLTs) with or without a stylet. ${ }^{1}$ We agree that there are no reports that implicate a stylet as the sole cause of tracheobronchial damage. However, we had a case of left mainstem bronchus laceration by an old type of left Broncho-Cath ${ }^{\mathbb{B}}$ (Mallinckrodt) using a stylet throughout the intubation procedure. Intubation was carried out by an experienced staff anaesthetist. Such a complication might be rare, but may lead to serious consequences.

Lieberman et al. reported that when the stylet had been removed just after the tip of the tube passed through the vocal cord, seven of 30 DLTs were initially placed into the right mainstem bronchus. In our experiences such cases are rare. For the last three years we have used left-sided DLT in about 150 cases and only in four were the tips of the tube placed into the right side. When we predict difficulty in left bronchial intubation, for example in cases with tracheal deviation by thoracic aortic aneurysm, we prefer to use a right-sided DLT first.

Consequently, we recommend that the stylet be removed just after the tip of the tube has passed through the vocal cords when using the BronchoCath $^{\circledR}$ DLT according to the product manufacturer's recommendation.

Satoshi Hagihira MD PHD, Masaki Takashina MD, Nobuyuki Taenaka MD PHD, Ikuto Yoshiya MD PHD Osaka University Medical School, 2-2 Yamadaoka, Suita 565, Japan

\section{REFERENCES}

1 Lieberman D, Littleford J, Horan T, Unrub H. Placement of left double-lumen endo-bronchial tubes with or without a stylet. Can J Anaesth 1996; 43: 238-42.

\section{$R E P L Y$}

We appreciate the comments of Drs. Hagihira, Takashina, Taenaka and Yoshiya regarding placement of left double-lumen tubes (DLTs) with or without a stylet. Before starting our study, we contacted four manufacturers of DLTs regarding recommendations in their product literature. All responded in writing and none had information or evidence (in the form of adverse event reports) that leaving the stylet in the DLT until final placement caused airway trauma.

Of interest, you report an incidence of inadvertent right mainstem intubation, using unstyletted left DLTs, which is considerably lower than the incidence reported in the published literature. ${ }^{1,2}$
Dianne Lieberman MD FRCPC

Judith Littleford MD FRCPC

Department of Anaesthesia, University of Manitoba, 60 Pearl Street, Winnipeg, Manitoba R3E IX2

\section{REFERENCES}

1 Alliaume $B$, Coddens J, Deloof $T$. Reliability of auscultation in positioning of double-lumen endobronchial tubes. Can J Anaesth 1992; 39: 687-90.

2 Smith GB, Hirsch NP, Ehrenwerth J. Placement of double-lumen endobronchial tubes. Br J Anaesth 1986; 58: 1317-20.

\section{Preventative not pre-emptive analgesia with piroxicam}

The recent interesting editorial ${ }^{1}$ on pre-emptive analgesia began by referring to a study ${ }^{2}$ of the perioperative use of piroxicam. By implication the study was investigating a pre-emptive analgesic role for piroxicam. Similarly in both the introduction and discussion the authors of the article mention pre-emptive analgesia. However, it is difficult to interpret the outcome of the study as showing a pre-emptive effect of the piroxicam.

Lack of any pharmacokinetic information on the "melt" piroxicam tablets or mention of the duration of operation does not support the assumption that equal concentrations of piroxicam were present at the effector site in the early recovery period. To support a pre-emptive effect it has to be shown that any greater analgesic effect of piroxicam in group one is due to the prevention of "wind-up" rather than to a difference in plasma concentrations during the period of observation in the recovery ward.

Standard texts suggest peak plasma levels occur $2-4$ hr after oral piroxicam. ${ }^{3}$ The effect of general anaesthesia may be to increase this time further. The single dose of fentanyl (presumably $1 \mu \mathrm{g} \cdot \mathrm{kg}^{-1}$, not 1 $\mathrm{mg} \cdot \mathrm{kg}^{-1}$ ) and atracurium suggest the duration of the laparoscopies resulted in patients in group 2 entering recovery before peak piroxicam levels were reached. Having had no piroxicam on admission to recovery it is not surprising that group 3 VAS were different from those of group 1. Dissimilar plasma levels during the early recovery period might explain the differing timing and numbers of requests for supplemental analgesia. Had the authors reported that the differences in analgesic consumption continued beyond the time when piroxicam levels might have equalised in the three groups, there would have been some support for the idea of there being a pre-emptive effect. 